\title{
Who will mentor the mentors?
}

\begin{abstract}
In the wake of the tragic suicide of a US graduate student, research universities need to adopt a different system of monitoring the quality of graduate students' supervision. Anonymous evaluation could be the answer.
\end{abstract}

\section{Carl Djerassi}

The suicide last August of Jason Altom, a Harvard graduate student, was widely reported in the media (see, for example, Nature 395, 823 \& 826; 1998; New York Times Sunday Magazine, 29 November 1998). All the articles cited Altom's suicide letter, in which he stated that if his working conditions had been overseen by a three-member faculty committee, instead of the conventional, exclusive relationship with one professor, "I know things would be different". The Harvard Crimson even equated the suicide note to a policy document. But could things really have been different?

If an oversight committee had existed in this case, it would have consisted of Altom's chosen mentor and $\mathrm{PhD}$ supervisor - Elias Corey, a Nobel laureate and arguably Harvard's most distinguished organic chemist - together with two other tenured professors, or perhaps one tenured and one untenured (who, thanks to Harvard's draconian tenure policy, would feel even less secure compared with their equivalents in other US universities). Altom's letter stated that an oversight committee would "provide protection for graduate students from abusive research advisors". How?

The committee members would have learned of such "abuse" (Altom's own undefined term) only if Altom - supposedly unable or unwilling to complain directly to his PhD advisor about allegedly "abusive" behaviour - had confided in one of them. What could the committee members have done? Confront the professor with his own student's unwillingness to communicate with him? What would this do to their continuing collegial relationship? In the assistant professor's case, such intervention might well seriously damage his or her own career.

\section{My alternative}

I would like to propose an alternative that seems to have been overlooked in all accounts of this laboratory tragedy. Based on my experience as a chemistry professor in another elite US research university, with several hundred graduate students and postdoctoral fellows under my supervision over four decades, I decided about ten years ago to illuminate our idiosyncratic professional behaviour in the guise of a fictional tetralogy, described by some colleagues as "washing dirty lab coats in public". In addition, I made the following proposal, which was uniformly shot down by several élite institutions as "opening a Pandora's box". But, as the father

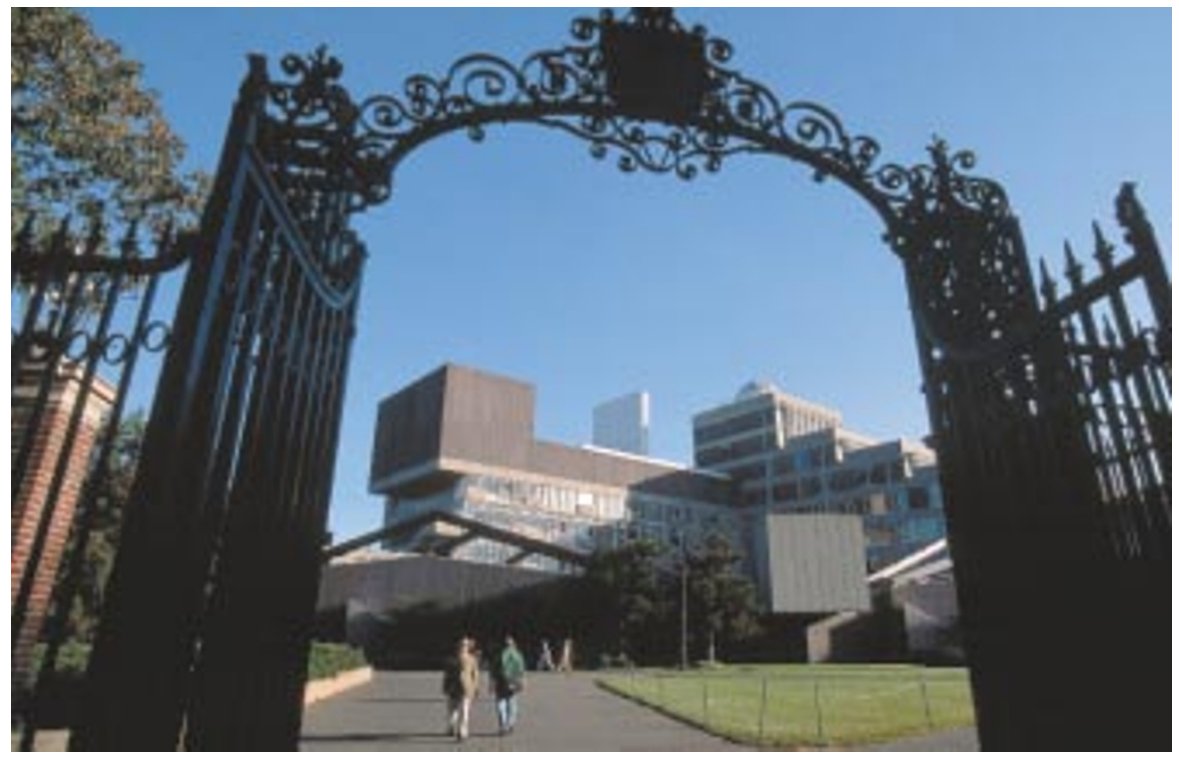

Would Harvard's PhD supervisors be open to assessment by their students?

of a suicide victim, I have become so obsessed by such tragedies that the first sentence in one of my 'science-in-fiction' novels (The Bourbaki Gambit) reads "What would you use to commit suicide?" The response was a chemist's answer (as was Altom's) — cyanide.

My proposed solution is simple. Complaints about "abusive research advisors" (Altom's terms) and other ill-defined behaviour must be handled anonymously, and hence must be lodged outside the intensely collegial and competitive departmental setting. The main US universities now require detailed evaluations of faculty by undergraduates, often with written assessment, as well as numerical ratings of various qualities. All this goes anonymously to a central office. Eventually, every professor, as well as the department chair and dean, receives a copy that forms part of their dossier in tenure or salary decisions.

Why not have annual evaluations by graduate students and postdocs of the many components of an appropriate mentor-disciple relationship? Occasional anonymous complaints by one student out of a dozen or more would then lead to very different conclusions — and action - about the mentor's performance than repeated critical commentary by half the research group. Is this not done because most universities give no training in supervision, automatically assuming that a novice assistant professor is a qualified mentor? With no standards for even assessing mentor performance, are they afraid even to have such issues raised? Or is it because the mentor would immediately guess the source of critical commentary? In chemistry such worries can often be dismissed because the sheer size of individual research groups, often exceeding 30 members, imposes a veil of anonymity. Even in small research groups, a dean's or ombudsperson's discretion could handle such problems.

As an experiment, some time ago I gave a simple questionnaire to a large group of graduate students in an élite US university, asking whether their $\mathrm{PhD}$ supervisor had discussed with them topics such as ethical behaviour in research, the publication practices of the research group (who writes the paper or decides the presence and order of authors?), freedom to discuss unpublished results, ability to pursue one's own ideas, details of the professor's attitude towards patents, and so on. The results were devastating. Depending on the question, 60-90 per cent of the students replied "no" or "never".

The social structure of the professor-graduate student relationship in the sciences is distinct. Although an undergraduate mentoring fiasco rarely causes permanent damage - mainly because other mentors are readily available — the same can hardly be said of graduate school, where the effects of this one-on-one mentor-disciple relationship may last a lifetime. Must people die before research universities will place serious emphasis on monitoring, evaluating and, crucially, on mentoring the mentors in their graduate school science faculties?

Carl Djerassi is in the Department of Chemistry, Stanford University, California 94305-5080, USA. e-mail:djerassi@stanford.edu 